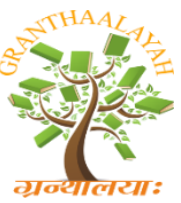

INTERNATIONAL JOURNAL OF RESEARCH GRANTHAALAYAH A knowledge Repository

Science

\title{
ADSORPTION CHARACTERISTICS OF ZIZYPHUS JUJUBA SEED SHELL ACTIVATED NANO POROUS CARBON FOR REMOVING COPPER (II) IONS FROM WASTE WATER
}

\author{
K Veeravelan $^{1}$, S Arivoli ${ }^{* 2}$, V Marimuthu ${ }^{3}$ \\ $1,{ }^{* 2,3} \mathrm{PG}$ and Research Department of Chemistry, Thiru Vi Ka Government Arts College, \\ Thiruvarur, Tamilnadu, India
}

DOI: https://doi.org/10.29121/granthaalayah.v4.i12.2016.2412

\begin{abstract}
In the present study, adsorption of copper (II) ions from aqueous solution by Activated Zizyphus Jujuba shell Nano Carbon was investigated under batch mode. The influence of solution $\mathrm{pH}$, sorbent dose, copper concentration, contact time and temperature was studied. The copper adsorption was favored with maximum adsorption at $\mathrm{pH}$ 6.5. Sorption equilibrium time was observed in $60 \mathrm{~min}$. The equilibrium adsorption data were correlated with Langmuir, Freundlich, Temkin, Dubinin-Radushkevich, Hurkins-Jura, Halsay, Radlich-Peterson, Jovanovic and BET isotherm models. The kinetics of the adsorption process was tested by pseudo-first-order, pseudo-second order, Elovich and Intra-particle diffusion models. It was shown that adsorption of copper could be described by the pseudo-second order kinetic model. Thermodynamic parameters such as Gibbs free energy $\left(\Delta \mathrm{G}^{0}\right)$, the enthalpy $\left(\Delta \mathrm{H}^{0}\right)$ and the entropy change of sorption $\left(\Delta S^{0}\right)$ have also been evaluated and it has been found that the adsorption process was spontaneous, feasible and endothermic in nature. The results indicated that Activated Zizyphus Jujuba shell Nano Carbon can be used as an effective and low-cost adsorbent to remove copper (II) from aqueous solution.
\end{abstract}

Keywords: Copper; Activated Zizyphus Jujuba Shell Nano Carbon; Isotherms and Kinetics Models.

Cite This Article: S Arivoli, K Veeravelan, and V Marimuthu. (2016). "ADSORPTION CHARACTERISTICS OF ZIZYPHUS JUJUBA SEED SHELL ACTIVATED NANO POROUS CARBON FOR REMOVING COPPER (II) IONS FROM WASTE WATER." International Journal of Research - Granthaalayah, 4(12), 226-241. https://doi.org/10.29121/granthaalayah.v4.i12.2016.2412.

\section{Introduction}

In view of rapid industrialization, the people all over the world are migrating to cities in search of jobs. This resulted into rapid increase in industrial activities which are important sources of 
environmental pollution. Industrial effluents contain high content of several heavy metal ions. Heavy metals are widely distributed in the environment and are ecologically important due to their high toxicity for living organisms including human beings ${ }^{1}$. Unlike organic pollutants, the majority of which are susceptible to biological degradation, heavy metals will not degrade into harmless end products. Thus, treatment of aqueous wastes containing soluble heavy metals requires concentration of the metals into a smaller volume followed by a secure disposal ${ }^{2}$. In particular, $\mathrm{Cu}^{2+}$ is a common metal ion found in effluents of a large number of industries. This metal is an essential element for life and is a micronutrient in trace amounts. However, a chronic exposure to $\mathrm{Cu}^{2+}$ is detrimental for human health ${ }^{3}$. To curtail heavy metal pollution problems, many processes have been developed that include chemical precipitation, electrode deposition, solvent extraction, ion exchange, activated carbon adsorption ${ }^{4,5}$ and biological methods ${ }^{6}$. The main limitations of these techniques are their low efficiency in metal ion removal at trace levels or the high cost. Hence adsorption is reported to be the most effective method for this purpose, which works at low concentration ${ }^{7}$.

In the present investigation the adsorption of Copper ion on activated nano carbon prepared from Zizyphus Jujuba shell by carbonization with sulphuric acid has been achieved. The kinetic and equilibrium adsorption data obtained were utilized to characterize the sample prepared ${ }^{8}$. The amounts and rates of adsorption of copper using above activated nano carbon from water were then measured. Three simplified kinetic models including pseudo first order, Pseudo second order equations and Elovich equations were used to describe the adsorption process.

\section{Materials \& Methods}

\section{Chemicals}

All reagents used in the experiments were of analytical (AR) grade and were obtained from Scientific Equipment Company, Trichy. Stock solutions of the test reagents were prepared by dissolving the copper ions in distilled water. $1000 \mathrm{mg} / \mathrm{L}$ of stock solution of copper $\left(\mathrm{CuSO}_{4}\right.$, $5 \mathrm{H}_{2} \mathrm{O}$ ) was prepared by dissolving accurately weighed 3.9296 grams of copper sulphate in 1000 $\mathrm{ml}$ distilled water. All experimental solutions were prepared by diluting the stock solution to the required concentration. The $\mathrm{pH}$ of each experimental solution was adjusted to the required initial $\mathrm{pH}$ value using dilute $\mathrm{HCl}$ (or) $\mathrm{NaOH}$ before mixing the adsorbent. The concentration of residual copper (II) was determined with atomic absorption spectrophotometer (Perkin Elemer 2380).

\subsection{Preparation of Adsorbent}

The natural plant material Zizyphus Jujuba shellused in the present investigations was collected from Antipalayam nearby Thiruvarur district the seed shell were washed with distilled water several times to remove the dirt and dust and was subsequently dried in a hot air oven at $110^{\circ} \mathrm{C}$. Afterward, carbonization of the Zizyphus Jujuba shellwas carried out by w/v ratio of concentrated sulphuric acid for 24 hour; the primary carbon was activated at $1100^{\circ} \mathrm{C}$ for $6 \mathrm{hrs}$ under optimized conditions to obtain activated nano carbon. The activated nano carbon was thereafter looked to room temperature in an insert atmosphere of nitrogen and washed with hot distilled water and $0.5 \mathrm{~N}$ Hydrochloric and until the $\mathrm{pH}$ of the material reached 7.0 the activated 
nano carbon was also dried in a hot air oven at $110^{\circ} \mathrm{C}$, to obtain the desired particular size $(40 \mathrm{~nm})$ and stored in desiccators for further use.

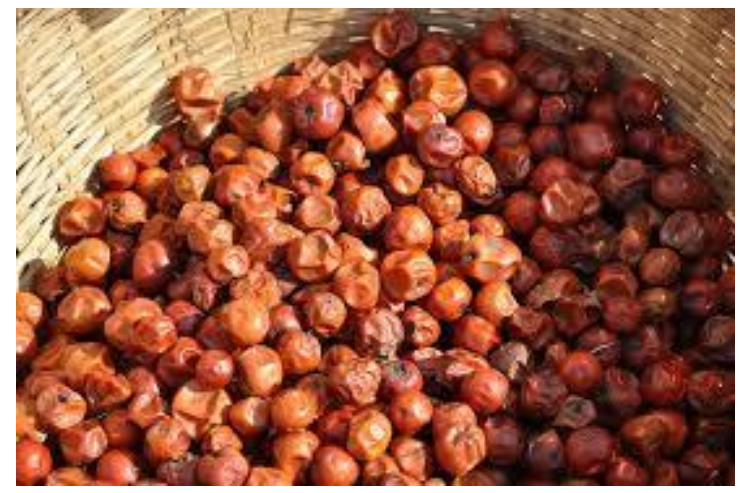

Figure1: Zizyphus Jujuba seed shell

\subsection{Batch Adsorption Studies}

Preliminary batch adsorption studies were conducted to determine the equilibrium time. Batch studies were performed by mixing $0.025 \mathrm{~g}$ of Copper ion with some of solution of different initial concentrations of Copper ion in $250 \mathrm{ml}$ stoppered conical flask. The dose of adsorbent was decided experimentally. All the adsorption experiments were conducted at $30^{\circ} \mathrm{C}$ to $60{ }^{\circ} \mathrm{C}$, at an agitation speed of $150 \mathrm{rpm}$ on the thermostat sharing water bath, the progress of adsorption was noted and equilibrium was achieved in $45 \mathrm{~min}$. After equilibrium, the adsorbent was separated from the age use phase by centrifugation at $1000 \mathrm{rpm}$ for to min using a centrifuge (Remi 24, India). The residual concentration of copper ions in the supernatant was determined by a UVVisible spectrophotometer at $618 \mathrm{~nm}$. The percentage removal of copper ions at equilibrium and the amount of copper ions transferred onto the surface of the adsorbent, qe ( $\mathrm{mg} / \mathrm{g}$ ) was calculated using the following relationships.

$$
\text { Percentage removal }=100\left(\mathrm{C}_{\mathrm{o}}-\mathrm{C}_{\mathrm{e}}\right) / \mathrm{C}_{\mathrm{o}}
$$

Amount of adsorbed copper ions molecules per $\mathrm{g}$ of solid

$$
\mathrm{Q}_{\mathrm{e}}=\left(\mathrm{C}_{\mathrm{O}}-\mathrm{C}_{\mathrm{e}}\right) \mathrm{v} / \mathrm{w}
$$

Where, $C_{o}(\mathrm{mg} / \mathrm{L})$ is the initial concentration of malachite green, $C_{e}(\mathrm{mg} / \mathrm{L})$ is the equilibrium concentration of copper ions, $\mathrm{V}$ is the volume of the solution $(\mathrm{L})$, and $\mathrm{w}(\mathrm{g})$ is the mass of the adsorbent.

\section{Result and Discussion}

\subsection{Characterization of Adsorbent}

Effect of operating variables on the adsorption of heavy copper ions onto Activated Zizyphus Jujuba shell the nano adsorbent of materials, AZJ-NC were used to absorb some mg of Copper ion respectively. 
The adsorption capacity of AZJ-NC is better than other, with the increase amount of AZJ-NC the removal of Copper ion increased obviously.

Table 1: Characteristics of the Adsorbent

\begin{tabular}{|l|l|}
\hline Analysis & Value \\
\hline $\mathrm{pH}_{\text {slurry }}$ & 5.5 \\
\hline $\mathrm{pH}_{\mathrm{zpc}}$ & 6.00 \\
\hline Moisture content, $\%$ & 0.105 \\
\hline Particle density, $\mathrm{g} \mathrm{cm}^{-3}$ & 0.285 \\
\hline Conductivity, $\mu \mathrm{S} / \mathrm{cm}^{2}$ & 41.63 \\
\hline Surface area, $\mathrm{m}^{2} / \mathrm{g}$ & 25.25 \\
\hline
\end{tabular}

\subsection{Effect It Contact Time}

Figure 2 illustrates the effects of contact time on the removal of Copper ion ions respectively for different initial copper ions concentrations; the changes in contact time exhibit approximately the same effects on the metal. Because of the utilization of the readily available active adsorption sites on the as surface, the adsorption of copper ions was rapid for the first $45 \mathrm{~min}$ for all the investigated initial copper ions concentrations. There after it continued at a slower rate and finally reached equilibrium as a result of saturation it as surface sites, for all copper ions, at the storied initial copper ions concentrations a sufficient contact time was determined as 45 min.

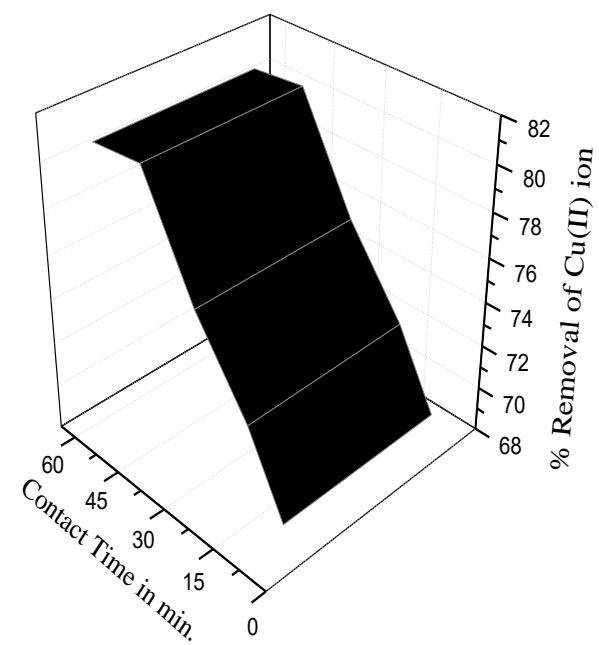

Fig:2- Effect of Contact Time on the Removal of $\mathrm{Cu}$ (II) ion $[\mathrm{Cu}(\mathrm{II})]=20 \mathrm{mg} / \mathrm{L} ;$ Temprature $=30^{\circ} \mathrm{C}$; Adsorbent dose $=0.025 \mathrm{~g} / 50 \mathrm{ml}$

\subsection{Effect of Adsorbent Concentration}

AZJ-NC with different concentrations were combined with a fixed 50ml, $20 \mathrm{mg} / \mathrm{L}$ of Copper ion respectively the adsorption of heavy copper ions increased with the increase of absorbent dose, and reached to a plateau at the appropriate dose of $125 \mathrm{mg}$ of AZJ-NC. The results were shown in the figure 3. 


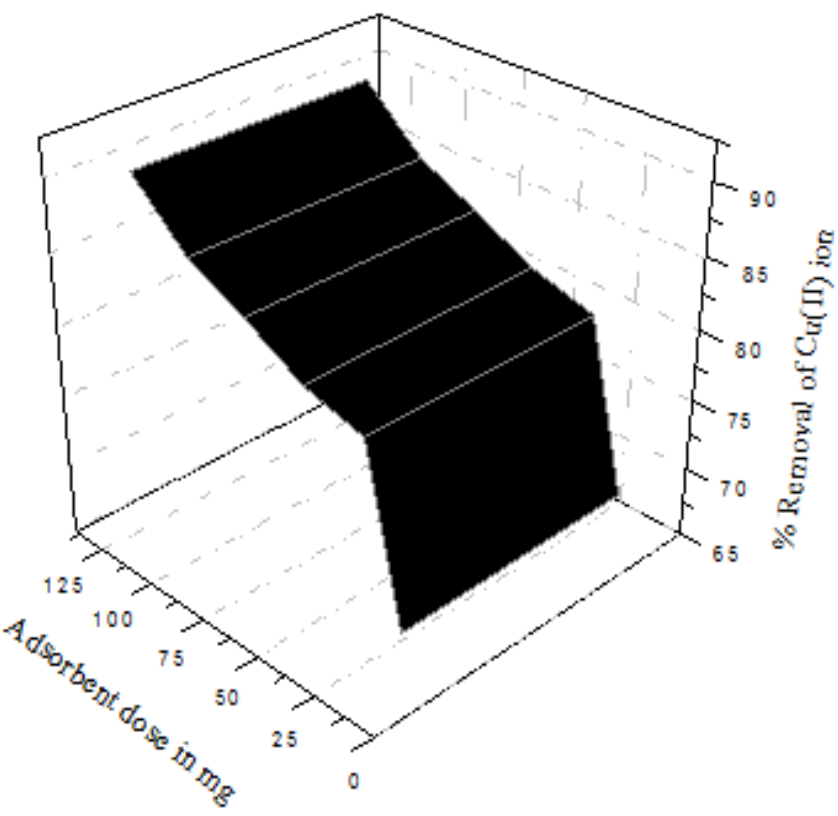

Fig;3-Effect of Adsorbent dose on the removal of $\mathrm{Cu}$ (II) ion $[\mathrm{Cv}$ (II) $]=20 \mathrm{mg} / \mathrm{L} ; \mathrm{C}$ ontact $\mathrm{Time} 45 \mathrm{~min} ;$ Tempratu re $30^{\circ} \mathrm{C}$

\subsection{Effect of Intoned pH on Adsorption}

The $\mathrm{pH}$ value of the solution was important controlling parameters in the adsorption process, the removal of copper ions increase significantly with increasing $\mathrm{pH}$ from 1 to 7 . The removal efficiencies of copper ions were low at $\mathrm{pH}<4$. The obvious decreasing of removal might be attributed to the repulsive forces between the positive surface charge of adsorbate and the positive copper ions. The result shows that the figure 4 .

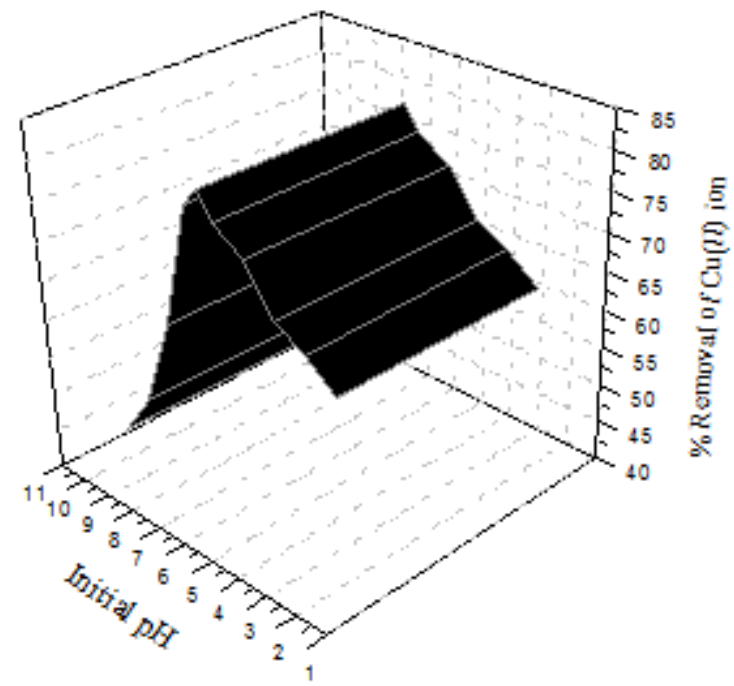

Fig;4- Effect of Initial pH on the ren oval of $\mathrm{Cu}$ (II) ion $[\mathrm{Cu}(\mathrm{II})]=20 \mathrm{mg} / \mathrm{L} ; \mathrm{Tem}$ prature $30^{\circ} \mathrm{C}$;Ad sorbent dose $=0.025 \mathrm{~g} / 50 \mathrm{~m} 1$ 


\subsection{Adsorption Isotherms}

Adsorption isotherm ${ }^{4-8}$ describes the relation between the amount or concentration of adsorbate that accumulates on the adsorbent and the equilibrium concentration of the dissolved adsorbate. Equilibrium studies were carried out by agitating a series of beakers containing $50 \mathrm{~mL}$ of $\mathrm{Cu}$ (II) solutions of initial concentration $20 \mathrm{mg} / \mathrm{L}$ with $0.025 \mathrm{~g}$ of activated nano carbon at $30{ }^{0} \mathrm{C}$ with a constant agitation. Agitation was provided for $1.0 \mathrm{~h}$, which is more than sufficient time to reach equilibrium.

\subsubsection{Freundlich Adsorption Isotherm}

The Freundlich adsorption isotherm is based on the equilibrium sorption on heterogeneous surfaces. This isotherm is derived from the assumption that the adsorption sites are distributed exponentially with respect to heat of adsorption. The adsorption isotherm is expressed by the following equation

$$
\mathrm{q}_{\mathrm{e}}=\mathrm{K}_{\mathrm{F}} \mathrm{C}_{\mathrm{e}}{ }^{1 / \mathrm{nF}}
$$

Which, can be linearized as

$$
\ln \mathrm{q}_{\mathrm{e}}=\ln \mathrm{K}_{\mathrm{F}}+\frac{1}{\mathrm{n}_{\mathrm{F}}} \ln \mathrm{C}_{\mathrm{e}}
$$

Where, $\mathrm{q}_{\mathrm{e}}$ is the amount of $\mathrm{Cu}(\mathrm{II})$ adsorbed at equilibrium $(\mathrm{mg} / \mathrm{g})$ and $\mathrm{C}_{\mathrm{e}}$ is the concentration of $\mathrm{Cu}(\mathrm{II})$ in the aqueous phase at equilibrium $(\mathrm{ppm}) . \mathrm{K}_{\mathrm{F}}(\mathrm{L} / \mathrm{g})$ and $1 / \mathrm{n}_{\mathrm{F}}$ are the Freundlich constants related to adsorption capacity and sorption intensity, respectively.

The Freundlich constants $\mathrm{K}_{\mathrm{F}}$ and $1 / \mathrm{n}_{\mathrm{F}}$ were calculated from the slope and intercept of the $\operatorname{lnq}_{\mathrm{e}} \mathrm{Vs}$ $\operatorname{lnC}_{\mathrm{e}}$ plot and the model parameters are shown in Table 3. The magnitude of $\mathrm{K}_{\mathrm{F}}$ showed that AZJ-NC had a high capacity for $\mathrm{Cu}(\mathrm{II})$ adsorption from the aqueous solutions studied. The Freundlich exponent, $\mathrm{n}_{\mathrm{F}}$, should have values in the range of 1 and 10 (i.e., $1 / \mathrm{n}_{\mathrm{F}}<1$ ) to be considered as favourable adsorption ${ }^{9}$. A $1 / \mathrm{n}_{\mathrm{F}}$ value of less than 1 indicated that $\mathrm{Cu}(\mathrm{II})$ is favorably adsorbed by AZJ-NC. The Freundlich isotherm did not show a good fit to the experimental data as indicated by SSE and Chi-square statistics.

\subsubsection{Langmuir Adsorption Isotherm}

The Langmuir adsorption isotherm is based on the assumption that all sorption sites possess equal affinity to the adsorbate. The Langmuir isotherm ${ }^{10}$ in a linear form can be represented as:

$$
\frac{C_{e}}{q_{e}}=\frac{1}{q_{m} K_{L}}+\frac{C_{e}}{q_{m}}
$$

Where, $\mathrm{q}_{\mathrm{e}}$ is the amount of $\mathrm{Cu}(\mathrm{II})$ adsorbed at equilibrium $(\mathrm{mg} / \mathrm{g}), \mathrm{C}_{\mathrm{e}}$ is the concentration of $\mathrm{Cu}$ (II) in the aqueous phase at equilibrium (ppm), $\mathrm{q}_{\mathrm{m}}$ is the maximum $\mathrm{Cu}$ (II) uptake (mg/g), and $\mathrm{K}_{\mathrm{L}}$ is the Langmuir constant related to adsorption capacity and the energy of adsorption $(\mathrm{g} / \mathrm{mg})$.

A linear plot of $\mathrm{C}_{\mathrm{e}} / \mathrm{q}_{\mathrm{e}} \mathrm{Vs} \mathrm{C}_{\mathrm{e}}$ was employed to determine the value of $\mathrm{q}_{\mathrm{m}}$ and $\mathrm{K}_{\mathrm{L}}$, and the data so obtained were also presented in Table 3. The model predicted a maximum value that could not 
be reached in the experiments. The value of $\mathrm{K}_{\mathrm{L}}$ decreased with an increase in the temperature. A high $\mathrm{K}_{\mathrm{L}}$ value indicates a high adsorption affinity. Weber and Chakraborti expressed the Langmuir isotherm in term of dimensionless constant separation factor or equilibrium parameter $\left(\mathrm{R}_{\mathrm{L}}\right)$ defined in the following equation:

$$
\mathrm{R}_{\mathrm{L}}=\frac{1}{1+\mathrm{K}_{\mathrm{L}} \mathrm{C}_{0}}
$$

Where, $\mathrm{C}_{0}$ is the initial $\mathrm{Cu}(\mathrm{II})$ concentration (ppm). Four scenarios can be distinguished:

The sorption isotherm is unfavorable when $\mathrm{R}_{\mathrm{L}}>1$, the isotherm is linear when $\mathrm{R}_{\mathrm{L}}=1$, The isotherm is favorable when $0<\mathrm{R}_{\mathrm{L}}<1$ and the isotherm is irreversible when $\mathrm{R}_{\mathrm{L}}=0$. The values of dimensionless separation factor $\left(\mathrm{R}_{\mathrm{L}}\right)$ for $\mathrm{Cu}(\mathrm{II})$ removal were calculated at different concentrations and temperatures. As shown in Table 4, at all concentrations and temperatures tested the values of $\mathrm{R}_{\mathrm{L}}$ for $\mathrm{Cu}(\mathrm{II})$ adsorptions on the AZJ-NC were less than 1 and greater than zero, indicating favorable adsorption.

The Langmuir isotherm showed a better fit to the adsorption data than the Freundlich isotherm. The fact that the Langmuir isotherm fits the experimental data well may be due to homogeneous distribution of active sites on the AZJ-NC surface, since the Langmuir equation assumes that the adsorbent surface is energetically homogeneous.

\subsubsection{Temkin Adsorption Isotherm}

The Temkin adsorption isotherm assumes that the heat of adsorption decreases linearly with the sorption coverage due to adsorbent-adsorbate interactions ${ }^{11}$ The Temkin isotherm equation is given as:

$$
\mathrm{q}_{\mathrm{e}}=\frac{\mathrm{RT}}{\mathrm{bT}} \ln \left(\mathrm{K}_{\mathrm{T}} \mathrm{C}_{\mathrm{e}}\right)
$$

Which, can be represented in the following linear form

$$
\mathrm{q}_{\mathrm{e}}=\frac{\mathrm{RT}}{\mathrm{b}} \ln \mathrm{K}_{\mathrm{T}}+\frac{\mathrm{RT}}{\mathrm{b}} \ln \mathrm{C}_{\mathrm{e}}
$$

Where, $\mathrm{K}_{\mathrm{T}}(\mathrm{L} / \mathrm{g})$ is the Temkin isotherm constant, $\mathrm{b}_{\mathrm{T}}(\mathrm{J} / \mathrm{mol})$ is a constant related to heat of sorption, $\mathrm{R}$ is the ideal gas constant $(8.314 \mathrm{~J} / \mathrm{mol} \mathrm{K})$, and $\mathrm{T}$ is absolute temperature $(\mathrm{K})$. A plot of $\mathrm{q}_{\mathrm{e}}$ versus $\operatorname{lnC}_{\mathrm{e}}$ enables the determination of isotherm constants $\mathrm{K}_{\mathrm{T}}$ and $\mathrm{b}_{\mathrm{T}}$ from the slope and intercept, The model parameters are listed in Table 3. The Temkin isotherm appears to provide a good fit to the $\mathrm{Cu}(\mathrm{II})$ adsorption data.

The adsorption energy in the Temkin model, $\mathrm{b}_{\mathrm{T}}$, is positive for $\mathrm{Cu}(\mathrm{II})$ adsorption from the aqueous solution, which indicates that the adsorption is endothermic. The experimental equilibrium curve is close to that predicted by Temkin model. Consequently, the adsorption isotherm of $\mathrm{Cu}(\mathrm{II})$ on $\mathrm{AZJ}-\mathrm{NC}$ can be described reasonably well by the Temkin isotherm.

\subsubsection{Hurkins-Jura Adsorption Isotherm}

The Hurkins-Jura ${ }^{12}$ adsorption isotherm can be expressed as: 
This can rearranged as follows:

$$
q_{e}=\sqrt{\frac{A_{H}}{B_{H}+\log C_{e}}} .
$$

$$
\frac{1}{\mathrm{q}_{\mathrm{e}}^{2}}=\frac{\mathrm{B}_{\mathrm{H}}}{\mathrm{A}_{\mathrm{H}}}-\frac{1}{\mathrm{~A}_{\mathrm{H}}} \log \mathrm{C} \text {. }
$$

Where, $A_{H}\left(g^{2} / L\right)$ and $B_{H}\left(\mathrm{mg}^{2} / L\right)$ are two parameters characterizing the sorption equilibrium.

The isotherm equation accounts for multilayer adsorption and can be explained by the existence of a heterogeneous pore distribution. The Harkins-Jura isotherm parameters are obtained from the plots of of $1 / \mathrm{q}_{\mathrm{e}}^{2}$ versus $\log \mathrm{C}_{\mathrm{e}}$ enables the determination of model parameters $\mathrm{A}_{\mathrm{H}}$ and $\mathrm{B}_{\mathrm{H}}$ from the slope and intercept.

\subsubsection{Halsay Adsorption Isotherm}

The Halsay ${ }^{13}$ adsorption isotherm can be given as

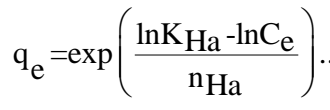

And, a linear form of the isotherm can be expressed as follows:

$$
\operatorname{lnq}_{\mathrm{e}}=\frac{\operatorname{lnK} \mathrm{Ha}}{\mathrm{n}_{\mathrm{Ha}}}-\frac{\ln \mathrm{C}_{\mathrm{e}}}{\mathrm{n}_{\mathrm{Ha}}}
$$

Where, $\mathrm{K}_{\mathrm{Ha}}(\mathrm{mg} / \mathrm{L})$ and $\mathrm{n}_{\text {На }}$ are the Halsay isotherm constants.

A plot of $\operatorname{lnq}_{\mathrm{e}} \mathrm{Vs} \ln \mathrm{C}_{\mathrm{e}}$, enables the determination of $\mathrm{n}_{\mathrm{Ha}}$ and $\mathrm{K}_{\mathrm{Ha}}$ from the slope and intercept. This equation is suitable for multilayer adsorption and the fitting of the experimental data to this equation attest to the heteroporous nature of adsorbent. The experimental data and the model predictions based on the non-linear form of the Halsay models. The model parameters are listed in Table 3. This result also shows that the adsorption of $\mathrm{Cu}(\mathrm{II})$ on AZJ-NC was not based on significant multilayer adsorption. The Halsay model is also not suitable to describe the adsorption of $\mathrm{Cu}(\mathrm{II})$ on $\mathrm{AZJ}-\mathrm{NC}$, because this model also assumes a multilayer behavior for the adsorption of adsorbate onto adsorbent.

\subsubsection{Redlich-Peterson Adsorption Isotherm}

The Radlich-Peterson ${ }^{14}$ adsorption isotherm contains three parameters and incorporates the features of Langmuir and Freundlich isotherms into a single equation. The general isotherm equation can be described as follows:

$$
\mathrm{q}_{\mathrm{e}}=\frac{\mathrm{K}_{\mathrm{R}} \mathrm{C}_{\mathrm{e}}}{1+\mathrm{a}_{\mathrm{R}} \mathrm{C}_{\mathrm{e}}^{\mathrm{g}}}
$$

The linear form of the isotherm can be expressed as follows:

$$
\ln \frac{\mathrm{C}_{\mathrm{e}}}{\mathrm{q}_{\mathrm{e}}}=\mathrm{glnC}_{\mathrm{e}}-\ln \mathrm{K}_{\mathrm{R}}
$$

Where, $\mathrm{K}_{\mathrm{R}}(\mathrm{L} / \mathrm{g})$ and $\mathrm{a}_{\mathrm{R}}(\mathrm{L} / \mathrm{mg})$ are the Radlich-Peterson isotherm constants and $\mathrm{g}$ is the exponent between 0 and 1 . There are two limiting cases: Langmuir form for $g=1$ and Henry's law for $\mathrm{g}=0$. 
A plot of $\ln \mathrm{C}_{\mathrm{e}} / \mathrm{q}_{\mathrm{e}}$ versus $\ln \mathrm{C}_{\mathrm{e}}$ enables the determination of isotherm constants $\mathrm{g}$ and $\mathrm{K}_{\mathrm{R}}$ from the slope and intercept. The values of $\mathrm{K}_{\mathrm{R}}$, presented in Table 3, indicate that the adsorption capacity of the AZJ-NC decreased with an increase temperature. Furthermore, the value of $g$ lies between 0 and 1 , indicating favorable adsorption.

\subsubsection{Dubinin-Radushkevich Adsorption Isotherm}

The Dubinin-Radushkevich ${ }^{15}$ adsorption isotherm is another isotherm equation [32]. It is assumed that the characteristic of the sorption curve is related to the porosity of the adsorbent. The linear form of the isotherm can be expressed as follows:

$$
\operatorname{lnq}_{\mathrm{e}}=\ln _{\mathrm{D}}-\mathrm{B}_{\mathrm{D}}\left[\mathrm{R} \ln \left(1+\frac{1}{\mathrm{C}_{\mathrm{e}}}\right)\right]^{2}
$$

Where, $\mathrm{Q}_{\mathrm{D}}$ is the maximum sorption capacity $(\mathrm{mol} / \mathrm{g})$, and $\mathrm{B}_{\mathrm{D}}$ is the Dubinin-Radushkevich constant $\left(\mathrm{mol}^{2} / \mathrm{kJ}^{2}\right)$. A plot of $\operatorname{lnq}_{\mathrm{e}} \mathrm{Vs} \mathrm{R}_{\mathrm{T}} \ln \left(1+1 / \mathrm{C}_{\mathrm{e}}\right)$ enables the determination of isotherm constants $\mathrm{B}_{\mathrm{D}}$ and $\mathrm{Q}_{\mathrm{D}}$ from the slope and intercept.

\subsubsection{Jovanovic Adsorption Isotherm}

The model of an adsorption surface considered by Jovanovic ${ }^{16}$ is essentially the same as that considered by Langmuir. The Jovanovic model leads to the following relationship [29]:

$$
\mathrm{q}_{\mathrm{e}}=\mathrm{q}_{\max }\left(1-\mathrm{e}^{\mathrm{K}_{\mathrm{J}} \mathrm{C}_{\mathrm{e}}}\right)
$$

The linear form of the isotherm can be expressed as follows:

$$
\operatorname{lnq}_{\mathrm{e}}=\operatorname{lnq}_{\max }-\mathrm{K}_{\mathrm{J}} \mathrm{C}_{\mathrm{e}}
$$

Where, $\mathrm{K}_{\mathrm{J}}(\mathrm{L} / \mathrm{g})$ is a parameter. $\mathrm{q}_{\max }(\mathrm{mg} / \mathrm{g})$ is the maximum Copper (II) uptake.

The $\mathrm{q}_{\max }$ is obtained from a plot of $\ln \mathrm{q}_{\mathrm{e}}$ and $\mathrm{C}_{\mathrm{e}}$. Their related parameters are listed in Table 3 .

By comparing the values of the error functions, it was found the Langmuir and Temkin models are best to fit the $\mathrm{Cu}(\mathrm{II})$ adsorption on the AZJ-NC. Both models show a high degree of correlation. This is clearly confirming the good fit of Langmuir and Temkin models with the experimental data for removal of $\mathrm{Cu}$ (II) from the solution.

\subsubsection{The Brunauer-Emmett-Teller (Bet) Isotherm Model}

Brunauer-Emmett-Teller (BET) ${ }^{17}$ isotherm is a theoretical equation, most widely applied in the gas-solid equilibrium systems. It was developed to derive multilayer adsorption systems with relative Concentration ranges from 10 to $50 \mathrm{mg} / \mathrm{L}$ corresponding to a monolayer coverage lying between 20 and $30 \mathrm{mg} / \mathrm{L}$. Its extinction model related to liquid-solid interface is exhibited as:

$$
\mathrm{q}_{\mathrm{e}}=\frac{\mathrm{q}_{\mathrm{s}} \mathrm{C}_{\mathrm{BET}} \mathrm{C}_{\mathrm{e}}}{\left(\mathrm{C}_{\mathrm{s}}-\mathrm{C}_{\mathrm{e}}\right)\left[1+\left(\mathrm{C}_{\mathrm{BET}}-1\right)\left(\mathrm{C}_{\mathrm{e}} / \mathrm{C}_{\mathrm{s}}\right)\right]}
$$

Where, CBET, Cs, qs and qe are the BET adsorption isotherm $(\mathrm{L} / \mathrm{mg})$, adsorbate monolayer saturation concentration $(\mathrm{mg} / \mathrm{L})$, theoretical isotherm saturation capacity $(\mathrm{mg} / \mathrm{g})$ and equilibrium adsorption capacity (mg/g), respectively. As $\mathrm{C}_{\mathrm{BET}}$ and $\mathrm{C}_{\mathrm{BET}}\left(\mathrm{C}_{\mathrm{e}} / \mathrm{C}_{\mathrm{s}}\right)$ is much greater than 1 , In the linear form as used is represented as 


$$
\frac{\mathrm{C}_{\mathrm{e}}}{\mathrm{q}\left(\mathrm{C}_{\mathrm{s}}-\mathrm{C}_{\mathrm{e}}\right)}=\frac{1}{\mathrm{q}_{\mathrm{s}} \mathrm{C}_{\mathrm{BET}}}+\left(\frac{\mathrm{C}_{\mathrm{BET}}-1}{\mathrm{q}_{\mathrm{s}} \mathrm{C}_{\mathrm{BET}}}\right)\left(\frac{\mathrm{C}_{\mathrm{e}}}{\mathrm{C}_{\mathrm{s}}}\right) .
$$

Where, $C_{e}$ is equilibrium Concentration $(\mathrm{mg} / \mathrm{l}), \mathrm{C}_{\mathrm{s}}$ is adsorbate monolayer saturation concentration $(\mathrm{mg} / \mathrm{l})$ and $\mathrm{C}_{\mathrm{BET}}$ is $\mathrm{BET}$ adsorption relating to the energy of surface interaction $(1 / \mathrm{mg})$.

\subsection{Kinetic Parameters}

The rate and mechanism of the adsorption process can be elucidated based on kinetic studies. $\mathrm{Cu}$ (II) adsorption on solid surface may be explained by two distinct mechanisms: (1) An initial rapid binding of $\mathrm{Cu}(\mathrm{II})$ molecules on the adsorbent surface; (2) relatively slow intra-particle diffusion. To analyze the adsorption kinetics of the $\mathrm{Cu}(\mathrm{II})$, the pseudo-first-order, the pseudosecond-order, and intra-particle diffusion models were applied ${ }^{18}$. Each of these models and their linear modes of them equations presented in below.

\section{Kinetic Models and Their Linear Forms}

\section{Model}

Pseudo-first-order

Pseudo-secondorder

\section{Nonlinear Form}

$$
\begin{aligned}
& \mathrm{dq} / \mathrm{d}_{1}=\mathrm{k}_{1}\left(\mathrm{q}_{\mathrm{e}}-\mathrm{q}_{1}\right) \\
& \mathrm{dq} / \mathrm{d}_{1}=\mathrm{k}_{2}\left(\mathrm{q}_{\mathrm{e}}-\mathrm{q}_{1}\right)^{2}
\end{aligned}
$$

Linear Form

$$
\begin{aligned}
& \ln \left(\mathrm{q}_{\mathrm{e}}-\mathrm{q}_{\mathrm{t}}\right)=\ln \mathrm{q}_{\mathrm{e}}-\mathrm{k}_{\mathrm{i}} \mathrm{t} \\
& \mathrm{t} / \mathrm{q}_{\mathrm{i}}=1 / \mathrm{k}^{2} \mathrm{q}_{\mathrm{e}}{ }^{2}+\left(1 / \mathrm{q}_{\mathrm{e}}\right) \mathrm{t}
\end{aligned}
$$

\section{Number of Equation}

Where, $\mathrm{q}_{\mathrm{e}}$ and $\mathrm{q}_{\mathrm{t}}$ refer to the amount of $\mathrm{Cu}(\mathrm{II})$ adsorbed $(\mathrm{mg} / \mathrm{g}$ ) at equilibrium and at any time, $\mathrm{t}$ (min), respectively and $\mathrm{k}_{1}(1 / \mathrm{min}), \mathrm{k}_{2}(\mathrm{~g} / \mathrm{mg}$.min) are the equilibrium rate constants of pseudo-first order and pseudo-second order models, respectively.

Pseudo-first order model is a simple kinetic model, which was proposed by Lagergren during 1898 and is used for estimation of the surface adsorption reaction rate. The values of $\ln \left(\mathrm{q}_{\mathrm{e}}-\mathrm{q}\right)$ were linearly correlated with $t$. The plot of $\ln \left(\mathrm{q}_{\mathrm{e}}-\mathrm{q}\right)$ ) Vs $t$ should give a linear relationship from which the values of $k_{1}$ were determined from the slope of the plot. In many cases, the first-order equation of Lagergren does not fit well with the entire range of contact time and is generally applicable over the initial stage of the adsorption processes.

In the pseudo-second order model, the slope and intercept of the t/qt Vs t plot were used to calculate the second-order rate constant, $\mathrm{k}_{2}$. The values of equilibrium rate constant $\left(\mathrm{k}_{2}\right)$ are presented in Table 6. According to Table 6, the value of $\mathrm{R}^{2}(0.999)$ related to the pseudo-second order model revealed that $\mathrm{Cu}$ (II) adsorption followed this model, which is in agreement with the results obtained by Karagoz et al. ${ }^{19}$ Hameed et al. ${ }^{20}$. Nevertheless, pseudo-first order and pseudosecond order kinetic models cannot identify the mechanism of diffusion of $\mathrm{Cu}$ (II) into the adsorbent pores.

\subsubsection{Simple Elovich Model}

The simple Elovich mode ${ }^{21}$ is expressed in the form,

$$
\mathrm{q}_{\mathrm{t}}=\alpha+\beta \ln \mathrm{t}
$$


Where, $\mathrm{q}_{\mathrm{t}}$ is the amount adsorbed at time $\mathrm{t}, \alpha$ and $\beta$ are the constants obtained from the experiment. A plot of $\mathrm{q}_{\mathrm{t}} \mathrm{Vs}$ lnt should give a linear relationship for the applicability of the simple Elovich kinetic. The Elovich kinetics of $\mathrm{Cu}$ (II) on to AZJ-NC for various initial concentrations $(10,20,30,40$ and $50 \mathrm{mg} / \mathrm{L})$ of volume $50 \mathrm{~mL}$ (each), adsorbent dose $0.025 \mathrm{~g}$, temperature $30{ }^{\circ} \mathrm{C}$ and $\mathrm{pH} 6.5$.

\subsubsection{The Elovich Equation}

The Elovich model equation is generally expressed as

$$
\mathrm{dq}_{\mathrm{t}} / \mathrm{d}_{\mathrm{t}}=\alpha \exp \left(-\beta \mathrm{q}_{\mathrm{t}}\right) \ldots \ldots \ldots \ldots(23)
$$

Where; $\alpha$ is the initial adsorption rate $\left(\mathrm{mg} \mathrm{g}^{-1} \mathrm{~min}^{-1}\right)$ and $\beta$ is the desorption constant $(\mathrm{g} / \mathrm{mg})$ during any one experiment. To simplify the Elovich equation. Chien and Clayton (1980) assumed $\alpha \beta \mathrm{t}>>\mathrm{t}$ and by applying boundary conditions $\mathrm{q}_{\mathrm{t}}=0$ at $\mathrm{t}=0$ and $\mathrm{q}_{\mathrm{t}}=\mathrm{q}_{\mathrm{t}}$ at $\mathrm{t}=\mathrm{t}$ Eq.(23) becomes:

$$
\mathrm{q}_{\mathrm{t}}=1 / \beta \ln (\alpha \beta)+1 / \beta \ln \mathrm{t}
$$

If $\mathrm{Cu}$ (II) ions adsorption fits with the Elovich model, a plot of $\mathrm{q}_{\mathrm{t}} \mathrm{vs}$. $\ln (\mathrm{t})$ should yield a linear relationship with a slope of $(1 / \beta)$ and an intercept of $(1 / \beta) \ln (\alpha \beta)$. The Elovich model parameters $\alpha, \beta$, and correlation coefficient $(\gamma)$ are summarized in table 6 . The experimental data such as the initial adsorption rate $(\alpha)$ adsorption constant $(\beta)$ and the correlation co-efficient $(\gamma)$ calculated from this model indicates that the initial adsorption $(\alpha)$ increases with temperature similar to that of initial adsorption rate $(\mathrm{h})$ in pseudo-second-order kinetics models. This may be due to increase the pore or active site on the AZJ-NC adsorbent.

\subsubsection{The Intraparticle Diffusion Model}

The kinetic results were analyzed by the Intraparticle diffusion model ${ }^{22}$ to elucidate the diffusion mechanism. The model is expressed as:

$$
\mathrm{q}_{\mathrm{t}}=\mathrm{K}_{\mathrm{id}} \mathrm{t}^{1 / 2}+\mathrm{I}
$$

Where, $I$ is the intercept and $K_{i d}$ is the intra-particle diffusion rate constant. The intercept of the plot reflects the boundary layer effect. Larger the intercept, greater is the contribution of the surface sorption in the rate controlling step. The calculated diffusion coefficient $\mathrm{K}_{\mathrm{id}}$ values are listed in Table 6. The $\mathrm{K}_{\mathrm{id}}$ value was higher at the higher concentrations. Intraparticle diffusion is the sole rate-limiting step if the regression of $\mathrm{q}_{\mathrm{t}}$ versus $\mathrm{t}^{1 / 2}$ is linear and passes through the origin. In fact, the linear plots at each concentration did not pass through the origin. This deviation from the origin is due to the difference in the rate of mass transfer in the initial and final stages of the sorption. This indicated the existence of some boundary layer effect and further showed that Intraparticle diffusion was not the only rate-limiting step.

It is clear from the Table 6 that the pseudo- second-order kinetic model showed excellent linearity with high correlation coefficient $\left(\mathrm{R}^{2}>0.99\right)$ at all the studied concentrations in comparison to the other kinetic models. In addition the calculated $\mathrm{q}_{\mathrm{e}}$ values also agree with the experimental data in the case of pseudo-second-order kinetic model. It is also evident from Table 6 that the values of the rate constant $\mathrm{k}_{2}$ decrease with increasing initial $\mathrm{Cu}$ (II) concentrations. This is due to the lower competition for the surface active sites at lower concentration but at 
higher concentration the competition for the surface active sites will be high and consequently lower sorption rates are obtained.

\subsection{Adsorption Thermodynamics}

Thermodynamic parameters ${ }^{23}$ were evaluated to confirm the adsorption nature of the present study. The thermodynamic constants, free energy change, enthalpy change and entropy change were calculated to evaluate the thermodynamic feasibility and the spontaneous nature of the process. Enthalpy change $(\Delta \mathrm{H})$, and entropy change $(\Delta \mathrm{S})$ may be determined from Van't Hoff equation:

$$
\ln K=\frac{\Delta S}{R}-\frac{\Delta H}{R T}
$$

By plotting ln $\mathrm{K}$ as ordinate and $1 / \mathrm{T}$ as abscissa, we will get $\Delta \mathrm{S}, \Delta \mathrm{H}$ and by using the following equation. We can get the value of have $\Delta \mathrm{S}, \Delta \mathrm{H}$ and by this equation, get the value of $\Delta \mathrm{G}$.

$$
\Delta G=\Delta H-T \Delta S
$$

Where, $\Delta \mathrm{G}$ is the free energy change $\left(\mathrm{kJ} \mathrm{mol}^{-1}\right), \mathrm{R}$ is the universal gas constant $\left(8.314 \mathrm{~J} \mathrm{~mol}^{-1}\right.$ $\left.\mathrm{K}^{-1}\right)$, $\mathrm{K}$ the thermodynamic equilibrium constant and $\mathrm{T}$ is the absolute temperature $(\mathrm{K})$.

$$
\begin{array}{r}
\Delta G=\Delta H-T \Delta S=-R T \ln K_{c} . \\
\ln K_{c}=\frac{\Delta S}{R}-\frac{\Delta H}{R T} \ldots \ldots \ldots \ldots \\
2.30 \log \frac{q_{e}}{C_{e}}=\frac{\Delta S}{R}-\frac{\Delta H}{R T} \ldots . \\
\log \frac{q_{e}}{C_{e}}=\frac{\Delta S}{R \times 2.303}-\frac{\Delta H}{R T \times 2.303} \ldots
\end{array}
$$

The values of $\Delta \mathrm{S}, \Delta \mathrm{H}, \Delta \mathrm{G}$ was obtained from a plot of $\log \left(\mathrm{q}_{\mathrm{e}} / \mathrm{C}_{\mathrm{e}}\right) \mathrm{vs} .1 / \mathrm{T}$.

Heat of reaction $(-\Delta \mathrm{H})$ for physical adsorption is reported to be 7 to $72 \mathrm{~kJ} / \mathrm{mol}$ in literature ${ }^{24}$. The value of $-\Delta \mathrm{H}$ range from -8 to $-11 \mathrm{~kJ} / \mathrm{mol}$ from Table- 5 which indicate that the nature of adsorption of $\mathrm{Cu}(\mathrm{II})$ on $\mathrm{AZJ}-\mathrm{NC}$ is physical adsorption. The negative value of $\Delta \mathrm{H} \& \Delta \mathrm{G}$ indicate exothermic and spontaneous process of adsorption of $\mathrm{Cu}(\mathrm{II})$ on $\mathrm{AZJ}-\mathrm{NC}$ respectively.

In order to support that physical adsorption is the predominant mechanism, the values of activation energy $(\mathrm{Ea})$ and sticking probability $\left(\mathrm{S}^{*}\right)$ were calculated from the experimental data. They were calculated using modified Arrhenius type equation related to surface coverage $(\theta)$ as follows:

$$
\begin{aligned}
\theta & =\left(1-\frac{\mathrm{C}_{\mathrm{e}}}{\mathrm{C}_{\mathrm{i}}}\right) \ldots \ldots \ldots \ldots . . . \\
S^{*} & =(1-\theta)_{e} \frac{-E_{a}}{R T} \ldots \ldots \ldots
\end{aligned}
$$

The sticking probability, $\mathrm{S}^{*}$, is a function of the adsorbate/adsorbent system under consideration but must satisfy the condition $0<\mathrm{S}^{*}<1$ and is dependent on the temperature of the system. The values of Ea and $S^{*}$ can be calculated from slope and intercept of the plot of $\ln (1-\theta)$ versus $1 / \mathrm{T}$ respectively. The calculated values were listed in Table 5. 
From Table 5 it is clear that the reaction is spontaneous in nature as $\Delta \mathrm{G}^{0}$ and $\Delta \mathrm{H}^{0}$ values are negative at all the temperature studied. Again positive value confirms that the sorption is endothermic in nature. The positive value of $\Delta S^{0}$ reflects the affinities of the adsorbents for the $\mathrm{Cu}(\mathrm{II})$. The result as shown in Table 5 indicate that the probability of the $\mathrm{Cu}(\mathrm{II})$ to stick on surface of biomass is very high as $\mathrm{S}^{*}<<1$, these values confirm that, the sorption process is physisorption.

\subsection{Desorption Studies}

Desorption studies help to elucidate the nature of adsorption and recycling of the spent adsorbent and the copper ions. If the adsorbed copper ions can be desorbed using neutral $\mathrm{pH}$ water, then the attachment of the copper ion of the adsorbent is by weak bonds. The effect of various reagents used for desorption studies. The results indicate that hydrochloric acid is a better reagent for desorption, because we could get more than $90 \%$ removal of adsorbed copper ion. The reversibility of adsorbed copper ion in mineral acid or base is in agreement with the $\mathrm{pH}$ dependent results obtained. The desorption of copper ion by mineral acids and alkaline medium indicates that the copper ion was adsorbed onto the AZJ-NC through physisorption as well as by chemisorptions mechanisms.

\section{Conclusion}

In this study, natural Activated Zizyphus Jujuba shell Nano Carbon of Indian origin was tested and evaluated as a possible adsorbent for removal of copper from its aqueous solution using batch sorption technique. The adsorption process is also dependent on numerous factors such as the solution $\mathrm{pH}$, adsorbent dosage, temperature, initial concentration and contact time. The percentage removal of copper ions decreased with an increase in the copper concentration while it increased with increase in contact time and adsorbent dose. The maximum removal was found between the $\mathrm{pH}$ ranges 2.0-6.5. The isotherm study indicates that the sorption data can be modeled by both Langmuir and BET isotherms. According to Dubinin-Radushkevich (D-R) isotherm model, adsorption of copper onto AZJ-NC was physisorption. The adsorption kinetics followed pseudo-second-order kinetic model. Intra-particle diffusion was not the sole rate controlling factor. Thermodynamic analysis suggests that the removal of copper from aqueous solution by AZJ-NC was a spontaneous and exothermic process. The present findings suggest that AZJ-NC may be used as an inexpensive and effective adsorbent without any treatment or any other modification for the removal of copper from aqueous solutions.

\section{References}

[1] S Arivoli, M Hema, S Parthasarathy and N Manju,. Adsorption dynamics of methylene blue by acid activated carbon. J. Chem. Pharm. Res, 2010, 2(5), 626-641.

[2] M Hema and S Arivoli, Rhodamine B adsorption by activated carbon: Kinetic and equilibrium studies, Indian Journal of Chemical Technology, 2009, 16(1), 38-45.

[3] V Vijayakumaran, S Arivoli, and S Ramuthai, Adsorption of nickel ion by low cost carbonkinetic, thermodynamic and equilibrium studies, 2009, 6 (S1), S347-S357.

[4] Ajamal, H., Mohammad, A. and Anwar, S. 2001. Sorption studies of heavy metals on teak leaves using thin layer and column chromatographic technique. Pollut. Res. 20 (3): 425 - 428. 
[5] Anbalagan, K. and Juliet, J.C. 2004. Adsorption of Cr (VI) ion onto activated amla dust: Adsorption isotherms and kinetics. Indian J. Chem. Technol. 43 A: 45:50.

[6] Brown, P., Jefcoat, I., Parrish, A., Dana, G., Sarah, S. and Graham, E. 2000. Evaluation of the adsorptive capacity of peanut hull pellets for heavy metals in solution. Adv. Environ. Res., 4(1): 19-29.

[7] Chien S H, Clayton W R, "Application of Elovich Equation to the kinetics of Phosphate release and sorption on soil", Soil Sci. Sco, Am. J. 44 :265 - 268, 1980.

[8] Hossain, M.A., Kumita, M., Michigami, Y. and Mori, S. 2005. Optimization of parameters for Cu (II) adsorption on used black tea leaves. Adsorption 11(5-6): 561-568.

[9] Jambulingam, M., Rehugadevi, N., Karthikeyan, S., Kiruthika, J., Patabhi. S. 2005. Adsorption of $\mathrm{Cr}(\mathrm{VI})$ from aqueous solution using a low cost activated nano carbon. Indian J Environ. Protect. 25(5): 458-63.

[10] Mohanty, K., Jha, M., Biswas, M.N. and Meikap, B.C. 2005. Removal of chromium (VI) from dilute aqueous solutions by activated nano carbon developed from Terminalia arjuna nuts activated with zinc chloride. Chem. Engg. Sc. 60(11): 3049-3059.

[11] Namasivayam, C. and Holl, W.H. 2004. Chromium (III) removal in tannery wastewaters using Chinese reed (Miscanthus Sinensis), a fast growing plant. Holz. Roh. Werkst. 62: $74-80$.

[12] Nikhel, K. 2005. Ecological management of polluted waters due to mining and allied industries. J. Indust. Pollut. Contamin. 12 (2):225-271.

[13] Rai, A.K and Surendra K. 1999. Removal of Cr (VI) by using brick kiln and flyash. Indian J. Environ. Health, 41(1): 65-73.

[14] Rao, M. and Bhole, A.G. 2001. Chromium removal by adsorption using fly ash and bagasse. J. Indian Water Works Assoc. 97: 997 - 1000.

[15] Rao, M. and Bhole, A.G. 2001. Chromium removal by adsorption using fly ash and bagasse. J. Indian Water Works Assoc. 97: 997 - 1000.

[16] Sharma, A. and Bhattacharya, D. 2005. Utilisation of biosorbent based on Azadirachta indica (Neem) leaves for removal of water soluble Metals. Indian J Environ. Chem. 12: 285-295.

[17] Sharma, Y.C. 2001. Adsorption of Cr (VI) onto wallastonite: Effect of pH. Indian J. Chem. Technol. 8: $191-194$.

[18] Shiny, K.J., Remani, K.N., Jalaja, T.K. and Sasidharan, V.K. 2004. Removal of chromium by two aquatic Pteridophytes. Indian J. Environ. Health 46: 249-251.

[19] Shrivastava, R.K., Ayachi, A.K. and Mora, M. 2001. Removal of Cr (VI) by utilization of Bidi leaves. Pollut. Res. 20(4): $639-643)$.

[20] Singh, I.B. and Singh, D.R. 2001. Hexavalent chromium removal using iron bearing industrial sludges: Indian J. Chem. Technol. 8: 487-495.

[21] Volesky, B. (2003).Sorption and Bi-sorption. Montreal-St. Lambert, Quebec, Canada, BV Sorbex Inc., 316p.

[22] Weber W J, Morris J C, "Kinetics of adsorption on Carbon from solution”. J, Sanitary Eng, Div. 90, 79, 1964.

[23] Wittbrodt, P.R.and Palmer C.D. 1995. Reduction of $\mathrm{Cu}$ (II) in the presence of excess soil fulvic acid. Environ. Sci. and Technol. 29: 255 - 265. 


\section{Appendix}

Table: 2. Equilibrium Parameters for the Adsorption of Copper Ion onto AZJ-NC

\begin{tabular}{|c|c|c|c|c|c|c|c|c|c|c|c|c|}
\hline \multirow{2}{*}{$\mathbf{M}_{\mathbf{0}}$} & \multicolumn{4}{|c|}{$\mathbf{C e}(\mathbf{M g} / \mathbf{L})$} & \multicolumn{4}{c|}{ Qe $(\mathbf{M g} / \mathbf{L})$} & \multicolumn{4}{c|}{ Removal \% } \\
\cline { 2 - 13 } & $\mathbf{3 0}^{\mathbf{}} \mathbf{C}$ & $\mathbf{4 0}^{\mathbf{0}} \mathbf{C}$ & $\mathbf{5 0}^{\mathbf{}} \mathbf{C}$ & $\mathbf{6 0}^{\mathbf{}} \mathbf{C}$ & $\mathbf{3 0}^{\mathbf{}} \mathbf{C}$ & $\mathbf{4 0}^{\mathbf{}} \mathbf{C}$ & $\mathbf{5 0}^{\mathbf{}} \mathbf{C}$ & $\mathbf{6 0}^{\mathbf{}} \mathbf{C}$ & $\mathbf{3 0}^{\mathbf{}} \mathbf{C}$ & $\mathbf{4 0}^{\mathbf{}} \mathbf{C}$ & $\mathbf{5 0}^{\mathbf{}} \mathbf{C}$ & $\mathbf{6 0}^{\mathbf{}} \mathbf{C}$ \\
\hline $\mathbf{1 0}$ & 1.813 & 1.313 & 1.064 & 1.038 & 16.37 & 17.37 & 17.87 & 17.92 & 81.87 & 86.87 & 89.36 & 89.62 \\
\hline $\mathbf{2 0}$ & 3.313 & 3.064 & 2.824 & 2.314 & 33.37 & 33.87 & 34.35 & 35.37 & 83.44 & 84.68 & 85.88 & 88.43 \\
\hline $\mathbf{3 0}$ & 6.584 & 6.014 & 5.313 & 4.964 & 46.83 & 47.97 & 49.37 & 50.07 & 78.05 & 79.95 & 82.29 & 83.45 \\
\hline $\mathbf{4 0}$ & 9.334 & 8.584 & 8.172 & 7.700 & 61.33 & 62.83 & 63.66 & 64.60 & 76.67 & 78.54 & 79.57 & 80.75 \\
\hline $\mathbf{5 0}$ & 13.56 & 13.11 & 12.84 & 12.11 & 72.87 & 73.78 & 74.33 & 75.79 & 72.87 & 73.78 & 74.33 & 75.79 \\
\hline
\end{tabular}

Table 3: Langmuir and Freundlich Isotherm Parameter for the Adsorption of Copper Ion onto AZJ-NC

\begin{tabular}{|c|c|c|c|c|c|}
\hline \multirow{2}{*}{ Model } & \multirow{2}{*}{ Constant } & \multicolumn{4}{|c|}{ Temperature $\left({ }^{\circ} \mathrm{C}\right)$} \\
\hline & & 30 & 40 & 50 & 60 \\
\hline \multirow{2}{*}{ Freundlich } & $\mathrm{K}_{\mathrm{f}}(\mathrm{mg} / \mathrm{g})(\mathrm{L} / \mathrm{mg})^{1 / \mathrm{n}}$ & 12.025 & 15.471 & 18.018 & 19.290 \\
\hline & $\mathrm{n}$ & 1.3919 & 1.5836 & 1.7164 & 1.7258 \\
\hline \multirow{2}{*}{ Langmuir } & $\mathrm{Q}_{\mathrm{m}}(\mathrm{mg} / \mathrm{g})$ & 141.07 & 116.57 & 106.94 & 107.12 \\
\hline & $\mathrm{b}(\mathrm{L} / \mathrm{mg})$ & 0.0799 & 0.1298 & 0.1745 & 0.1954 \\
\hline \multirow{2}{*}{ Temkin } & $\mathrm{b}_{\mathrm{T}}(\mathrm{J} / \mathrm{mol})$ & 27.452 & 24.581 & 23.022 & 23.433 \\
\hline & $\mathrm{K}_{\mathrm{T}}(\mathrm{L} / \mathrm{mg})$ & 0.9934 & 1.0813 & 1.1250 & 1.1439 \\
\hline \multirow{2}{*}{ Hurkins-Jura } & $A_{H}\left(g^{2} / L\right)$ & -270.69 & -329.46 & -371.94 & -387.81 \\
\hline & $\mathrm{B}_{\mathrm{H}}\left(\mathrm{mg}^{2} / \mathrm{L}\right)$ & -1.0397 & -1.0202 & -1.0030 & -0.9756 \\
\hline \multirow{2}{*}{ Halsay } & $\mathrm{K}_{\mathrm{Ha}}(\mathrm{mg} / \mathrm{L})$ & 31.865 & 76.502 & 142.964 & 165.286 \\
\hline & $\mathrm{n}_{\mathrm{Ha}}$ & 1.3919 & 1.5836 & 1.7164 & 1.7258 \\
\hline \multirow{2}{*}{$\begin{array}{l}\text { Radlich- } \\
\text { Peterson }\end{array}$} & $\mathrm{g}$ & 0.2815 & 0.3685 & 0.4174 & 0.4206 \\
\hline & $\mathrm{K}_{\mathrm{R}}(\mathrm{L} / \mathrm{g})$ & 0.0832 & 0.0646 & 0.0555 & 0.0518 \\
\hline \multirow{2}{*}{$\begin{array}{c}\text { Dubinin- } \\
\text { Radushkevich }\end{array}$} & $\mathrm{q}_{\mathrm{s}}(\mathrm{mg} / \mathrm{g})$ & 63.108 & 60.232 & 59.834 & 62.970 \\
\hline & $\mathrm{K}_{\mathrm{D}} \times 10^{-4} \mathrm{~mol}^{2} \mathrm{~kJ}^{-2}$ & 1.4865 & 1.4693 & 1.4632 & 1.4725 \\
\hline \multirow{2}{*}{ Jovanovic } & $\mathrm{K}_{\mathrm{J}}(\mathrm{L} / \mathrm{g})$ & 0.1142 & 0.1129 & 0.1105 & 0.1153 \\
\hline & $\mathrm{q}_{\max }(\mathrm{mg} / \mathrm{g})$ & 18.558 & 20.359 & 21.943 & 22.738 \\
\hline \multirow{2}{*}{ BET } & $\mathrm{C}_{\mathrm{BET}}(\mathrm{L} / \mathrm{mg})$ & 4.7517 & 6.9696 & 9.8542 & 11.3460 \\
\hline & qs (mg/g) & 0.2105 & 0.1435 & 0.1015 & 0.0881 \\
\hline
\end{tabular}

Table 4: Dimensionless Seperation Factor $\left(\mathrm{R}_{\mathrm{L}}\right)$ for the Adsorption of Copper Ion onto AZJ-NC

\begin{tabular}{|c|c|c|c|c|}
\hline \multirow{2}{*}{$\left(\mathbf{C}_{\mathbf{i}}\right)$} & \multicolumn{4}{|c|}{ Temperature $^{\circ} \mathbf{C}$} \\
\cline { 2 - 5 } & $\mathbf{3 0}^{\mathbf{}} \mathbf{C}$ & $\mathbf{4 0}^{\mathbf{0}} \mathbf{C}$ & $\mathbf{5 0}^{\mathbf{}} \mathbf{C}$ & $\mathbf{6 0}^{\mathbf{}} \mathbf{C}$ \\
\hline $\mathbf{2 5}$ & 0.3336 & 0.2356 & 0.1865 & 0.1699 \\
\hline $\mathbf{5 0}$ & 0.2002 & 0.1335 & 0.1028 & 0.0928 \\
\hline $\mathbf{7 5}$ & 0.1430 & 0.0932 & 0.0710 & 0.0639 \\
\hline $\mathbf{1 0 0}$ & 0.1112 & 0.0715 & 0.0542 & 0.0487 \\
\hline $\mathbf{1 2 5}$ & 0.0910 & 0.0581 & 0.0438 & 0.0393 \\
\hline
\end{tabular}


Table 5: Thermodynamic Parameter for the Adsorption of Copper Ion onto AZJ-NC

\begin{tabular}{|c|c|c|c|c|c|c|c|c|}
\hline \multirow{2}{*}{$\mathbf{C}_{\mathbf{0}}$} & \multicolumn{4}{|c|}{$\Delta \mathbf{G}^{\circ}$} & \multirow{2}{*}{$\Delta \mathbf{H}^{\circ}$} & \multirow{2}{*}{$\Delta \mathbf{S}^{\circ}$} & \multirow{2}{*}{$\mathbf{E}_{\mathbf{a}}$} & \multirow{2}{*}{$\mathbf{S}^{*}$} \\
\cline { 2 - 6 } & $\mathbf{3 0}^{\circ} \mathbf{C}$ & $\mathbf{4 0}^{\circ} \mathbf{C}$ & $\mathbf{5 0}^{\circ} \mathbf{C}$ & $\mathbf{6 0}^{\circ} \mathbf{C}$ & & & & \\
\hline $\mathbf{1 0}$ & -3797.8 & -4917.0 & -5715.8 & -5968.0 & 18.490 & 74.183 & 15948.4 & 0.0003 \\
\hline $\mathbf{2 0}$ & -4072.9 & -4449.0 & -4848.7 & -5631.2 & 11.226 & 50.242 & 9652.92 & 0.0037 \\
\hline $\mathbf{3 0}$ & -3196.4 & -3599.9 & -4125.1 & -4479.8 & 10.080 & 43.809 & 8152.13 & 0.0086 \\
\hline $\mathbf{4 0}$ & -2996.5 & -3376.2 & -3651.4 & -3969.7 & 6.0622 & 32.029 & 5266.54 & 0.0287 \\
\hline $\mathbf{5 0}$ & -2489.5 & -2691.7 & -2855.1 & -3159.1 & 4.0686 & 21.596 & 3023.76 & 0.0820 \\
\hline
\end{tabular}

Table 6: The Kinetic Parameters for the Adsorption of Copper Ion onto AZJ-NC

\begin{tabular}{|c|c|c|c|c|c|c|c|c|c|c|c|}
\hline \multirow[b]{2}{*}{$\mathrm{C}_{0}$} & \multirow{2}{*}{$\operatorname{Temp}^{\circ} \mathrm{C}$} & \multicolumn{4}{|c|}{ Pseudo second order } & \multicolumn{3}{|c|}{ Elovich model } & \multicolumn{3}{|c|}{ Intraparticle diffusion } \\
\hline & & $\underline{q_{e}}$ & $\mathbf{k}_{2}$ & $\gamma$ & $\mathbf{h}$ & $\alpha$ & $\beta$ & $\gamma$ & $\mathbf{K}_{\mathrm{id}}$ & $\gamma$ & $\mathbf{C}$ \\
\hline \multirow{4}{*}{25} & 30 & 16.58 & 0.0163 & .9901 & .469 & 90.30 & .4615 & .9939 & .0167 & .9889 & 1.903 \\
\hline & 40 & 18.66 & 0.0099 & 0.9902 & 3.434 & 125.1 & 0.4787 & 0.9866 & .1327 & .9881 & 1.697 \\
\hline & 50 & 18.65 & 0.0166 & 59 & 5.784 & 75.26 & 7172 & 9868 & & 9909 & 1.799 \\
\hline & 60 & 18.65 & 0.0177 & 0.9929 & 6.165 & 147.9 & 0.7557 & 0.9879 & .0783 & 0.9920 & 1.809 \\
\hline \multirow{4}{*}{$\mathbf{5 0}$} & 30 & 36.71 & & .9963 & 4.676 & 53.94 & .2003 & .9922 & & .9942 & 1.605 \\
\hline & & 36.97 & & 0.9909 & 5.277 & 80.66 & 0.2097 & 0.9877 & & 909 & 1.635 \\
\hline & 50 & 37.33 & 0.0044 & 0.9943 & 6.129 & 130.4 & 0.2200 & 0.9872 & 0.1472 & 0.9935 & 1.667 \\
\hline & 60 & 37.83 & & & 81 & & & & & & 1.710 \\
\hline \multirow{4}{*}{75} & 3 & 49.84 & 0.0037 & 0.9912 & 9.272 & 735.1 & 0.1997 & 0.9926 & 0.1174 & 0.9892 & 1.671 \\
\hline & 40 & 51.57 & 0.0041 & 0.9970 & 10.83 & 595.3 & 0.1837 & \begin{tabular}{|l|}
0.9867 \\
\end{tabular} & & 0.9883 & 1.683 \\
\hline & 50 & 53.59 & 0.0034 & 0.9955 & 9.895 & 249.8 & 0.1576 & 0.9890 & 0.1413 & 0.9875 & 1.664 \\
\hline & 60 & 53.21 & 0.0050 & 0.9971 & 14.14 & 104.6 & 0.1856 & 0.9868 & 64 & 0.9877 & 1.719 \\
\hline \multirow{4}{*}{100} & & & & & 8 & .3 & & & & 396 & 1.660 \\
\hline & 40 & 67.27 & 0.0035 & 0.9904 & 15.68 & 585.5 & 336 & 0.9883 & 02 & 0.9905 & 1.668 \\
\hline & 50 & 67.92 & 0.0037 & 0.9934 & 17.09 & 805.5 & 0.1369 & 0.9930 & 248 & 0.9926 & 1.684 \\
\hline & 60 & 68.88 & & 0.9965 & 17.58 & 921.8 & 0.1370 & 0.9886 & & 0.9937 & 1.694 \\
\hline \multirow{4}{*}{125} & 30 & 77.80 & 0.0022 & 0.9912 & 13.13 & 519.9 & 0.1162 & 0.9888 & .1314 & 0.9924 & 1.615 \\
\hline & 40 & 78.84 & 0.0021 & 0.9972 & 13.25 & 516.8 & 0.1145 & 0.9881 & 0.1317 & 0.9945 & 1.620 \\
\hline & 50 & 79.02 & 0.0023 & 0.9906 & 14.30 & 851.5 & 0.1212 & 0.9888 & 0.1226 & 0.9892 & 1.640 \\
\hline & 60 & 80.76 & 0.0021 & 0.9930 & 13.70 & 588.8 & 0.1133 & 0.9917 & 0.1295 & 0.9892 & 1.634 \\
\hline
\end{tabular}

*Corresponding author.

E-mail address: arivu6363@gmail.com 